\title{
KAJIAN KATEGORI TEPAT GUNA LAHAN DALAM PENERAPAN KONSEP GREEN BUILDING DI ITENAS
}

\author{
Kandita $^{1)}$, Emma Akmalah'), Ira Irawati' ${ }^{2}$ \\ 1) Jurusan Teknik Sipil, Institut Teknologi Nasional, Bandung 40124 \\ Email: kanditaroes@yahoo.com \\ ${ }^{2)}$ Jurusan Perencanaan Wilayah \& Kota, Institut Teknologi Nasional, Bandung 40124
}

\begin{abstract}
ABSTRAK
Industri konstruksi merupakan sektor penting yang memiliki kontribusi besar terhadap pembangunan sosioekonomi suatu negara. Di sisi lain, sejalan dengan pertumbuhan dan perkembangan masyarakat, kegiatan konstruksi juga berdampak besar terhadap kondisi lingkungan alami. Untuk mengatasi masalah tersebut, banyak negara telah menerapkan konsep pembangunan berkelanjutan dan green building. The Green Building Council Indonesia (GBCI) dengan perangkat penilaiannya yang disebut dengan GREENSHIP, adalah badan utama di Indonesia yang bertugas untuk mempromosikan penerapan konsep pembangunan berkelanjutan serta mengevaluasi rancangan dan konstruksi suatu bangunan. Penelitian ini bertujuan untuk mengevaluasi dua gedung di Itenas sesuai dengan kategori tepat guna lahan pada GREENSHIP. Pengumpulan data dilakukan dengan cara observasi, pengukuran dan wawancara. Selanjutnya dilakukan analisis komparatif, deskriptif, dan SWOT untuk menghasilkan strategi dan usulan kebijakan. Hasil dari penelitian ini menunjukkan bahwa gedung lama memenuhi $50 \%$ dan gedung baru memenuhi $41,176 \%$ dari point penilaian GRRENSHIP.
\end{abstract}

Kata Kunci

Pembangunan Berkelanjutan, Green Building, GREENSHIP

\section{PENDAHULUAN}

Ketidakseimbangan ekosistem di bumi makin hari makin terasa dengan adanya proses peningkatan suhu rata-rata atmosfer yang diakibatkan oleh panas matahari yang meningkat. Perubahan suhu dari tahun ke tahun semakin mengkhawatirkan karena adanya pemanasan global (global warming).

Manusia merupakan pelaku utama dalam menyebabkan permasalahan yang ada.Oleh karena kebutuhan manusia yang tidak dapat dipisahkan dari kemajuan zaman, maka pembangunan mulai dari sarana dan prasarana untuk menunjang kebutuhan tersebut diperlukan.Namun semakin pesatnya pembangunan yang dilakukan di Indonesia pada umumnya tidak diiringi dengan pertimbangan kerusakan lingkungan, oleh karena itu diperlukan suatu konsep yang mengharuskan setiap bangunan memiliki sistem berkelanjutan yang dapat menjaga kelestarian alam serta kualitas udara yang ada.Konsep green building merupakan salah satu konsep yang berperan dalam pembangunan berkelanjutan.

Penelitian ini dilakukan di Kampus Itenas yang merupakan salah satu kampus swasta yang ada di Kota Bandung.Sesuai dengan visi Itenas pada tahun 2030 [1] yang mengatakan bahwa Itenas ikut berperan aktif dalam pembangunan berkelanjutan di lingkup nasional dan global, maka perlu ada tindakan langsung agar dapat mencapai visi tersebut.Penelitian ini diharapkan mampu melihat sejauh mana Kampus Itenas telah menerapkan konsep green building dengan melakukan penilaian sesuai dengan kriteria green building pada kategori Tepat Guna Lahan dalam perangkat GREENSHIP untuk selanjutnya memberikan rekomendasi yang diharapkan menjadi salah satu tolok ukur ke depannya.

\section{TINJAUAN PUSTAKA}

\subsection{Konsep Pembangunan Berkelanjutan}

Pembangunan berkelanjutan adalah pembangunan yang berusaha memenuhi kebutuhan hari ini tanpa mengurangi kemampuan generasi mendatang untuk memenuhi kebutuhannya [2].Salah satu konsep yang berperan dalam penerapan pembangunan berkelanjutan adalah green building.

Green building merupakan bangunan baru yang direncanakan dan dilaksanakan, atau bangunan yang sudah terbangun yang dioperasikan dengan memperhatikan faktor-faktor lingkungan/ekosistem dan memenuhi kinerja: bijak guna lahan, kualitas udara dalam ruangan, hemat air, hemat energi, hemat bahan, dan mengurangi limbah [3].

\subsection{Perangkat GREENSHIP}

GREENSHIP merupakan sistem rating perangkat tolak ukur bangunan hijau di Indonesia yang dibuat oleh GBCI untuk menilaipencapaian konsep bangunan ramah lingkungan dari suatu bangunan.GREENSHIP sendiri dibuat dengan 
mempertimbangkan kondisi, karakter alam, serta peraturan dan standar yang berlaku di Indonesia.Perangkat ini disusun dengan melibatkan para pelaku sektor bangunan yang ahli di bidangnya seperti arsitek, industri bangunan, teknisi mekanikal elektrikal, desainer interior, arsitek lansekap, dan lainnya. GBCI didirikan pada tahun 2009 oleh para profesional di sektor perancangan dan konstruksi bangunan gedung yang memiliki kepedulian kepada penerapan konsep bangunan hijau.GBCI bertujuan untuk melakukan transformasi pasar serta diseminasi kepada masyarakat dan pelaku bangunan untuk menerapkan prinsip-prinsip bangunan hijau, khususnya disektor industri bangunan gedung di Indonesia.

\section{METODOLOGI PENELITIAN}

Penelitian ini dilakukan mulai dari identifikasi masalah yang ada, yaitu sejauh mana pemahaman Itenas tentang konsep green building pada kategori Tepat Guna Lahan serta sejauh mana Kampus Itenas telah menerapkannya. Selanjutnya dilakukan studi literatur terkait dengankonsep pemanasan global, pembangunan berkelanjutan, konsep green building, dan analisis SWOT. Kemudian dilakukan perencanaan alat ukur,berupa observasi, pengukuran, dan wawancara.Setelah alat ukur sesuai atau valid selanjutnya dilakukan pengumpulan data,yaitu data primer dan data sekunder.Data primer terkait penerapan konsep green building dalam kategori tepat guna lahan didapat dari hasil wawancara kepada pihak yang terkait di Itenas.Selanjutnya observasi dilakukan untuk mengetahui keadaan eksisting Gedung 1 dan Gedung Student Centerterkait material yang digunakan.Selain itu dilakukan pengukuran untuk mengetahui luas RTH, luas RTNH, dan Jarak fasilitas umum dari tapak.Data sekunder didapat dari indikator green building menurut GBCI yaitu perangkat penilaian GREENSHIP serta data luas gedung dari penelitian sebelumnya. Setelah semua data yang dibutuhkan terpenuhi, selanjutnya data diolah sesuai dengan kriteria penilaian perangkat GREENSHIP pada kategori Tepat Guna Lahan yaitu GREENSHIP untuk Bangunan Baru Versi 1.2 [4] untuk Gedung 1 dan GREENSHIP Existing Building Version 1.1 [5] untuk Gedung Student Center, data yang sudah diolah memberikan output berupa nilai maksimum untuk Gedung 1 dan Gedung Student Center. Dari hasil penilaian akan dianalisis dengan menggunakan 3 metode analisis yaitu analisis komparatif, analisis deskriptif, dan analisis SWOT agar dapat ditarik kesimpulan dan rekomendasiterkait kekurangan tentang kriteria green building yang belum terpenuhi.

\section{HASIL PENELITIAN}

Pada bagian ini akan dijelaskan hasil yang didapat dari observasi, pengukuran, dan wawancara.

\subsection{Pembahasan Hasil Penelitian untuk Gedung 1}

Berdasarkan hasil pengamatan dan pengukuran untuk Gedung 1, diperoleh data sebagai berikut dapat dilihat pada Tabel 1 .

Tabel 1. Penilaian GREENSHIP untuk Gedung 1

\begin{tabular}{|c|c|c|c|c|c|c|}
\hline Kode & Rating & & Tolok Ukur & $\begin{array}{l}\text { Point } \\
\text { Max }\end{array}$ & $\begin{array}{l}\text { Base } \\
\text { Line }\end{array}$ & Target \\
\hline \multirow[t]{3}{*}{ ASD1 } & \multirow[t]{3}{*}{$\begin{array}{l}\text { Pemilihan } \\
\text { Tapak } \\
\text { (Site } \\
\text { Selection) }\end{array}$} & $1 \mathrm{~A}$ & $\begin{array}{l}\text { Memilih daerah } \\
\text { pembangunan yang } \\
\text { dilengkapi minimal } \\
\text { delapan dari } 12 \\
\text { prasarana sarana kota }\end{array}$ & 1 & 1 & 1 \\
\hline & & $\overline{1 B}$ & $\begin{array}{l}\text { Memilih daerah } \\
\text { pembangunan dengan } \\
\text { ketentuan KLB }>3\end{array}$ & 1 & - & - \\
\hline & & 2 & $\begin{array}{l}\text { Melakukan revitalisasi } \\
\text { dan pembangunan di } \\
\text { atas lahan yang bernilai } \\
\text { negatif dan tak terpakai } \\
\text { karena bekas } \\
\text { pembangunan atau } \\
\text { dampak negatif } \\
\text { pembangunan }\end{array}$ & 1 & 0 & 1 \\
\hline \multirow[t]{4}{*}{ ASD 2} & \multirow[t]{4}{*}{$\begin{array}{l}\text { Aksesibilitas } \\
\text { Komunitas } \\
\text { (Community } \\
\text { Accesibility) }\end{array}$} & 1 & $\begin{array}{l}\text { Terdapat minimal tujuh } \\
\text { jenis fasilitas umum } \\
\text { dalam jarak pencapaian } \\
\text { jalan utama sejauh } \\
1.500 \mathrm{~m} \text { dari tapak }\end{array}$ & 1 & 1 & 1 \\
\hline & & 2 & $\begin{array}{l}\text { Membuka akses pejalan } \\
\text { kaki selain ke jalan } \\
\text { utama di luar tapak yang } \\
\text { menghubungkannya } \\
\text { dengan jalan skunder } \\
\text { dan/atau lahan milik } \\
\text { orang lain sehingga } \\
\text { tersedia akses ke } \\
\text { minimal tiga fasilitas } \\
\text { umum sejauh } 300 \mathrm{~m} \\
\text { jarak pencapaian pejalan } \\
\text { kaki }\end{array}$ & 1 & 1 & 1 \\
\hline & & 3 & $\begin{array}{l}\text { Menyediakan } \\
\text { fasilitas/akses yang } \\
\text { aman, nyaman, dan } \\
\text { bebas dari perpotongan } \\
\text { dengan akses kendaraan } \\
\text { bermotor untuk } \\
\text { menghubungkan secara } \\
\text { langsung bangunan } \\
\text { dengan bangunan lain, } \\
\text { di mana terdapat } \\
\text { minimal tiga fasilitas } \\
\text { umum dan/atau dengan } \\
\text { stasiun transportasi } \\
\text { masal }\end{array}$ & 2 & 0 & 2 \\
\hline & & $\overline{4}$ & $\begin{array}{l}\text { Membuka lantai dasar } \\
\text { gedung sehingga dapat } \\
\text { menjadi akses pejalan } \\
\text { kaki yang aman dan } \\
\text { nyaman selama } \\
\text { minimum } 10 \text { jam sehari }\end{array}$ & 2 & 2 & 2 \\
\hline ASD 3 & $\begin{array}{l}\text { Transportasi } \\
\text { Umum } \\
\text { (Public } \\
\text { Transporta- } \\
\text { tion) }\end{array}$ & $1 \mathrm{~A}$ & $\begin{array}{l}\text { Adanya halte atau } \\
\text { stasiun transportasi } \\
\text { umum dalam jangkauan } \\
300 \mathrm{~m} \text { (walking } \\
\text { distance) dari gerbang } \\
\text { lokasi bangunan dengan } \\
\text { tidak memperhitungkan } \\
\text { panjang jembatan } \\
\text { penyeberangan dan } \\
\text { ramp }\end{array}$ & 1 & 1 & 1 \\
\hline
\end{tabular}




\begin{tabular}{|c|c|c|c|c|c|c|}
\hline & & 1B & $\begin{array}{l}\text { Menyediakan shuttle } \\
\text { busuntuk pengguna } \\
\text { tetap gedung dengan } \\
\text { jumlah unit minimum } \\
\text { untuk } 10 \% \text { pengguna } \\
\text { tetap gedung }\end{array}$ & 1 & - & - \\
\hline & & 2 & $\begin{array}{l}\text { Menyediakan fasilitas } \\
\text { jalur pedestrian di } \\
\text { dalam area gedung } \\
\text { untuk menuju ke } \\
\text { stasiun transportasi } \\
\text { umum terdekat yang } \\
\text { aman dan nyaman } \\
\text { dengan } \\
\text { mempertimbangkan } \\
\text { Peraturan Menteri } \\
\text { Pekerjaan Umum } \\
\text { 30/PRT/M/2006 } \\
\text { mengenai Pedoman } \\
\text { Teknis Fasilitas dan } \\
\text { Aksebilitas pada } \\
\text { Bangunan Gedung } \\
\text { dan Lingkungan } \\
\text { Lampiran 2B }\end{array}$ & 1 & 0 & - \\
\hline \multirow[t]{2}{*}{ ASD 4} & \multirow[t]{2}{*}{$\begin{array}{c}\text { Fasilitas } \\
\text { Pengguna } \\
\text { Sepeda } \\
\text { (Bicycle } \\
\text { Facility) }\end{array}$} & 1 & $\begin{array}{l}\text { Adanya tempat parkir } \\
\text { sepeda yang aman } \\
\text { sebanyak satu unit } \\
\text { parkir per } 20 \\
\text { pengguna gedung } \\
\text { hingga maksimal } 100 \\
\text { unit parkir sepeda }\end{array}$ & 1 & 0 & 1 \\
\hline & & 2 & $\begin{array}{l}\text { Apabila tolok ukur } 1 \\
\text { diatas terpenuhi, perlu } \\
\text { tersedianya shower } \\
\text { sebanyak } 1 \text { unit untuk } \\
\text { setiap } 10 \text { parkir } \\
\text { sepeda }\end{array}$ & 1 & 0 & 1 \\
\hline \multirow[t]{3}{*}{ ASD 5} & \multirow[t]{3}{*}{$\begin{array}{c}\text { Lansekap } \\
\text { pada Lahan } \\
\text { (Site } \\
\text { Lanscaping) }\end{array}$} & $1 \mathrm{~A}$ & $\begin{array}{l}\text { Adanya area lansekap } \\
\text { berupa vegetasi } \\
\text { (softscape) yang bebas } \\
\text { dari bangunan taman } \\
\text { (hardscape) yang } \\
\text { terletak di atas } \\
\text { permukaan tanah } \\
\text { seluas minimal 40\% } \\
\text { luas total lahan. } \\
\text { Luas area yang } \\
\text { diperhitungkan adalah } \\
\text { termasuk yang } \\
\text { tersebut Prasyarat } 1, \\
\text { taman di atas } \\
\text { basement, roof } \\
\text { garden, terrace } \\
\text { garden, dan wall } \\
\text { garden, dengan } \\
\text { mempertimbangkan } \\
\text { Peraturan Menteri PU } \\
\text { No. 5/PRT/M/2008 } \\
\text { mengenai Ruang } \\
\text { Terbuka Hijau (RTH) } \\
\text { Pasal 2.3.1 tentang } \\
\text { Kriteria Vegetasi } \\
\text { untuk Pekarangan }\end{array}$ & 1 & 0 & 1 \\
\hline & & $1 \mathrm{~B}$ & $\begin{array}{l}\text { Bila tolok ukur } 1 \\
\text { dipenuhi, setiap } \\
\text { penambahan 5\% area } \\
\text { lansekap dari luas } \\
\text { total lahan mendapat } \\
\text { nilai } 1\end{array}$ & 1 & 0 & 1 \\
\hline & & 2 & $\begin{array}{l}\text { Penggunaan tanaman } \\
\text { yang telah } \\
\text { dibudidayakan secara } \\
\text { lokal dalam skala } \\
\text { provinsi, sebesar } 60 \% \\
\text { luas tajuk dewasa }\end{array}$ & 1 & 0 & 1 \\
\hline
\end{tabular}

\begin{tabular}{|c|c|c|c|c|c|c|}
\hline & & & $\begin{array}{l}\text { terhadap luas area } \\
\text { lansekap pada ASD } 5 \\
\text { tolok ukur } 1\end{array}$ & & & \\
\hline \multirow[t]{5}{*}{ ASD 6} & $\begin{array}{c}\text { Iklim Mikro } \\
\text { (Micro } \\
\text { Climate })\end{array}$ & $1 \mathrm{~A}$ & $\begin{array}{l}\text { Menggunakan berbagai } \\
\text { material untuk } \\
\text { menghindari efek heat } \\
\text { island pada area atap } \\
\text { gedung sehingga nilai } \\
\text { albedo (daya refleksi } \\
\text { panas matahari) } \\
\text { minimum } 0,3 \text { sesuai } \\
\text { dengan perhitungan }\end{array}$ & 1 & - & - \\
\hline & & $1 \mathrm{~B}$ & $\begin{array}{l}\text { Menggunakan green } \\
\text { roof sebesar 50\% dari } \\
\text { luas atap yang tidak } \\
\text { digunakan untuk } \\
\text { mechanical electrical } \\
\text { (ME), dihitung dari luas } \\
\text { tajuk }\end{array}$ & 1 & 0 & 1 \\
\hline & & 2 & $\begin{array}{l}\text { Menggunakan berbagai } \\
\text { material untuk } \\
\text { menghindari efek heat } \\
\text { island pada area } \\
\text { perkerasan non-atap } \\
\text { sehingga nilai albedo } \\
\text { (daya refleksi panas } \\
\text { matahari) minimum } 0,3 \\
\text { sesuai dengan } \\
\text { perhitungan }\end{array}$ & 1 & 1 & 1 \\
\hline & & $3 \mathrm{~A}$ & $\begin{array}{l}\text { Desain lansekap berupa } \\
\text { vegetasi (softscape) } \\
\text { pada sirkulasi utama } \\
\text { pejalan kaki } \\
\text { menunjukkan adanya } \\
\text { pelindung dari panas } \\
\text { akibat radiasi matahari }\end{array}$ & 1 & 0 & 1 \\
\hline & & $3 \mathrm{~B}$ & $\begin{array}{l}\text { Desain lansekap berupa } \\
\text { vegetasi (softscape) } \\
\text { pada sirkulasi utama } \\
\text { pejalan kaki } \\
\text { menunjukkan adanya } \\
\text { pelindung dari terpaan } \\
\text { angin kencang }\end{array}$ & 1 & 0 & 1 \\
\hline \multirow[t]{5}{*}{ ASD 7} & $\begin{array}{l}\text { Manajemen } \\
\text { Air Limpasan } \\
\text { Hujan } \\
\text { (Stormwater } \\
\text { Management) }\end{array}$ & $1 \mathrm{~A}$ & $\begin{array}{l}\text { Pengurangan beban } \\
\text { volume limpasan air } \\
\text { hujan ke jaringan } \\
\text { drainase kota dari lokasi } \\
\text { bangunan hingga } 50 \%, \\
\text { yang dihitung } \\
\text { menggunakan nilai } \\
\text { intensitas curah hujan }\end{array}$ & 1 & 0 & 1 \\
\hline & & 1B & $\begin{array}{l}\text { Pengurangan beban } \\
\text { volume limpasan air } \\
\text { hujan ke jaringan } \\
\text { drainase kota dari lokasi } \\
\text { bangunan hingga } 85 \% \text {, } \\
\text { yang dihitung } \\
\text { menggunakan nilai } \\
\text { intensitas curah hujan }\end{array}$ & 2 & - & - \\
\hline & & 2 & $\begin{array}{l}\text { Menunjukan adanya } \\
\text { upaya penanganan } \\
\text { pengurangan beban } \\
\text { banjir lingkungan dari } \\
\text { luar lokasi bangunan }\end{array}$ & 1 & 0 & 1 \\
\hline & & 3 & $\begin{array}{l}\text { Menggunakan } \\
\text { teknologi-teknologi } \\
\text { yang dapat mengurangi } \\
\text { debit limpasan air hujan }\end{array}$ & 1 & 0 & 1 \\
\hline & & & Total Point & 17 & 7 & 17 \\
\hline
\end{tabular}

\section{Catatan:}

Point Max = poin maksimal pada setiap kriteria.

Base Line $=$ poin yang didapat dari hasil penelitian.

Target $=$ poin yang ditargetkan pada penelitian.

terhadap luas area

lansekap pada ASD

Menggunakan berbaga

roof sebesar $50 \%$ dar

luas atap yang tidak

Menggunakan berbagai

sehingga nilai albedo

daya refleksi panas

sesuai dengan

vegetasi (softscape)

pelindung dari panas

vegetasi (softscape)

pejalan kaki

ngin kencan

drainase kota dari loka

yang dihitun

Pengurangan beban

olume limpasan air

bangunan hingga $85 \%$,

luas tajuk dewasa 


\subsection{Pembahasan Hasil Penelitian untuk Gedung Student Center}

Berdasarkan hasil pengamatan dan pengukuran untuk Gedung Student Center, diperoleh data sebagai berikut dapat dilihat pada Tabel 2 .

Tabel 2. Penilaian GREENSHIP untuk Gedung Student Center

\begin{tabular}{|c|c|c|c|c|c|c|}
\hline Kode & Rating & & Tolok Ukur & $\begin{array}{l}\text { Point } \\
\text { Max }\end{array}$ & $\begin{array}{l}\text { Base } \\
\text { Line }\end{array}$ & $\begin{array}{l}\text { Tar- } \\
\text { get }\end{array}$ \\
\hline \multirow[t]{5}{*}{ ASD 1} & $\begin{array}{c}\text { Community } \\
\text { Accessibility }\end{array}$ & 1 & $\begin{array}{l}\text { Terdapat minimal } 5 \\
\text { jenis fasilitas umum } \\
\text { dalam jarak pencapaian } \\
\text { jalan utama sejauh } 500 \\
\text { m dari tapak }\end{array}$ & 1 & 1 & 1 \\
\hline & & $2 \mathrm{~A}$ & $\begin{array}{l}\text { Adanya halte atau } \\
\text { stasiun transportasi } \\
\text { umum dalam jangkauan } \\
300 \text { m dari gerbang } \\
\text { lokasi bangunan dengan } \\
\text { perhitungan di ljuar } \\
\text { jembatan penyebrangan } \\
\text { dan ramp }\end{array}$ & 1 & 1 & 1 \\
\hline & & $2 \mathrm{~B}$ & $\begin{array}{l}\text { Adanya halte atau } \\
\text { tempat tunggu } \\
\text { permanen, yang } \\
\text { didukung dengan } \\
\text { adanya teluk bus (bus } \\
\text { bay) atau jalur henti bus } \\
\text { (lay by) }\end{array}$ & 2 & - & - \\
\hline & & 3 & $\begin{array}{l}\text { Menyediakan fasilitas } \\
\text { jalur pejalan kaki di } \\
\text { dalam area gedung } \\
\text { untuk menju ke halte } \\
\text { atau stasiun transportasi } \\
\text { umum terdekat, yang } \\
\text { aman dan nyaman } \\
\text { sesuai dengan Permen } \\
\text { PU No. 30/PRT/M/2006 } \\
\text { Bab 2B }\end{array}$ & 1 & 1 & 1 \\
\hline & & 4 & $\begin{array}{l}\text { Menyediakan fasilitas } \\
\text { pejalan kaki yang aman, } \\
\text { nyaman dan bebas dari } \\
\text { perpotongan akses } \\
\text { kendaraan bermotor } \\
\text { untuk menghubungkan } \\
\text { minimal } 3 \text { fasilitas } \\
\text { umum diatas dan atau } \\
\text { dengan stasiun } \\
\text { transportasi masal }\end{array}$ & 2 & 0 & 2 \\
\hline \multirow[t]{2}{*}{ ASD 2} & $\begin{array}{c}\text { Motor Vehicle } \\
\text { Reduction }\end{array}$ & 1 & $\begin{array}{l}\text { Adanya pengurangan } \\
\text { pemakaian kendaraan } \\
\text { bermotor pribadi dengan } \\
\text { implementasi dari salah } \\
\text { satu opsi: car pooling, } \\
\text { feeder bus, pengurangan } \\
\text { reservedparking dengan } \\
\text { intensif lain dari } \\
\text { building management ke } \\
\text { tenant, atau diskriminasi } \\
\text { tarif parker }\end{array}$ & 1 & 1 & 1 \\
\hline & & 2 & $\begin{array}{l}\text { Adanya parkir sepeda } \\
\text { yang aman sebanyak } 1 \\
\text { unit parkir per } 30 \\
\text { pengguna gedung tetap, } \\
\text { hingga maksimal } 100 \\
\text { unit parkir sepeda }\end{array}$ & 1 & 0 & 1 \\
\hline ASD 3 & $\begin{array}{c}\text { Site } \\
\text { Landscaping }\end{array}$ & 1 & $\begin{array}{l}\text { Adanya area lansekap } \\
\text { berupa vegetasi } \\
\text { (softscape) yang bebas } \\
\text { dari bangunan taman }\end{array}$ & 1 & 0 & 1 \\
\hline
\end{tabular}

\begin{tabular}{|c|c|c|c|c|c|c|}
\hline Kode & Rating & & Tolok Ukur & $\begin{array}{l}\text { Point } \\
\text { Max }\end{array}$ & $\begin{array}{l}\text { Base } \\
\text { Line }\end{array}$ & $\begin{array}{l}\text { Tar- } \\
\text { get }\end{array}$ \\
\hline & & & $\begin{array}{l}\text { (hardscape) yang } \\
\text { terletak di atas } \\
\text { permukaan tanah seluas } \\
\text { minimal } 30 \% \text { luas total } \\
\text { lahan. } \\
\text { Luas area yang } \\
\text { diperhitungkan adalah } \\
\text { termasuk taman di atas } \\
\text { basement, roof garden, } \\
\text { terrace garden dan wall } \\
\text { garden. } \\
\text { Formasi tanaman sesuai } \\
\text { dengan Permen PU No. } \\
\text { 5/PRT/M/2008 } \\
\text { mengenai Ruang } \\
\text { Terbuka Hijau (RTY) } \\
\text { pasal 2.3.1 tentang } \\
\text { Kriteria Vegetasi untuk } \\
\text { Pekarangan }\end{array}$ & & & \\
\hline & & 2 & $\begin{array}{l}\text { Penambahan nilai } 1 \text { poin } \\
\text { untuk setiap } \\
\text { penambahan } 10 \% \text { luas } \\
\text { tapak untuk penggunaan } \\
\text { area lansekap } \\
\end{array}$ & $1-2$ & 0 & 1 \\
\hline & & 3A & $\begin{array}{l}\text { Penggunaan } 60 \% \\
\text { tanaman lokal yang } \\
\text { berasal dari nursery } \\
\text { lokal dengan jarak } \\
\text { maksimal } 1.000 \mathrm{~km} \\
\end{array}$ & 1 & 1 & 1 \\
\hline & & 3B & $\begin{array}{l}\text { Penggunaan tanaman } \\
\text { produktif, minimal 10\% } \\
\text { dari area lansekap }\end{array}$ & 1 & - & - \\
\hline \multirow[t]{3}{*}{ ASD 4} & $\begin{array}{l}\text { Heat Island } \\
\text { Effect }\end{array}$ & 1A & $\begin{array}{l}\text { Menggunakan bahan } \\
\text { yang nilai albedo rata- } \\
\text { rata minimal } 0,3 \text { sesuai } \\
\text { dengan perhitungan } \\
\text { pada area atap gedung } \\
\text { yang tertutup perkerasan }\end{array}$ & 1 & - & - \\
\hline & & 1B & $\begin{array}{l}\text { Menggunakan green } \\
\text { roof sebesar 50\% dari } \\
\text { luas atap yang tidak } \\
\text { digunakan untuk } \\
\text { mechanical electrical } \\
\text { (ME), dihitung dari luas } \\
\text { tajuk }\end{array}$ & 1 & 0 & 1 \\
\hline & & 2 & $\begin{array}{l}\text { Menggunakan bahan } \\
\text { yang nilai albedo rata- } \\
\text { rata minimal } 0,3 \text { sesuai } \\
\text { dengan perhitungan } \\
\text { pada area non atap yang } \\
\text { tertutup perkerasan }\end{array}$ & 1 & 1 & 1 \\
\hline \multirow[t]{2}{*}{ ASD 5} & $\begin{array}{l}\text { Storm Water } \\
\text { Management }\end{array}$ & $1 \mathrm{~A}$ & $\begin{array}{l}\text { Pengurangan beban } \\
\text { volume limpasan air } \\
\text { hujan dari luas lahan ke } \\
\text { jaringan drainase kota } \\
\text { sebesar } 50 \% \text { total } \\
\text { volume hujan harian } \\
\text { rata-rata yang dihitung } \\
\text { berdasarkan perhitungan } \\
\text { debit air hujan pada } \\
\text { bulan basah }\end{array}$ & 1 & 0 & 1 \\
\hline & & 1B & $\begin{array}{l}\text { Pengurangan beban } \\
\text { volume limpasan air } \\
\text { hujan dari luas lahan ke } \\
\text { jaringan drainase kota } \\
\text { sebesar } 75 \% \text { total } \\
\text { volume hujan harian } \\
\text { rata-rata yang dihitung } \\
\text { berdasarkan perhitungan } \\
\text { debit air hujan pada } \\
\text { bulan basah }\end{array}$ & 2 & - & - \\
\hline ASD 6 & $\begin{array}{c}\text { Site } \\
\text { Management }\end{array}$ & 1 & $\begin{array}{l}\text { Memiliki dan } \\
\text { menerapkan Standar }\end{array}$ & 1 & 0 & 1 \\
\hline
\end{tabular}




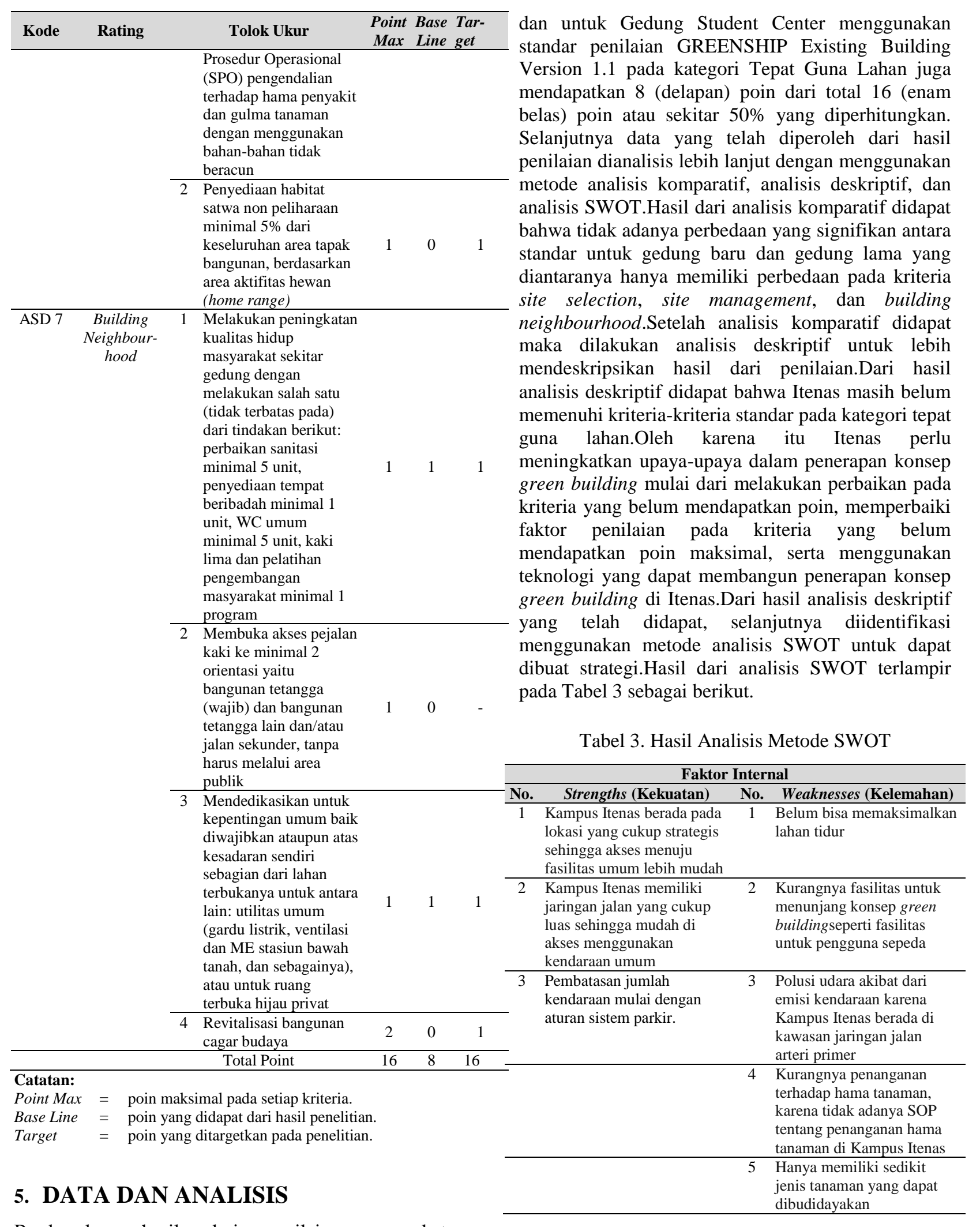

Berdasarkan hasil dari penilaian perangkat GREENSHIP untuk kategori Tepat Guna Lahan dan hasil analisis menggunakan metode SWOT didapat rekomendasi untuk Gedung 1 dengan menggunakan standar penilaian GREENSHIP untuk Bangunan Baru Versi 1.2 pada kategori Tepat Guna Lahan mendapatkan 7 (tujuh) poin dari total 17 (tujuh belas) poin yang diperhitungkan atau sekitar $41,176 \%$ poin, 
Tabel 3. Hasil Analisis Metode SWOT Lanjutan

\begin{tabular}{|c|c|c|c|}
\hline \multicolumn{4}{|c|}{ Faktor Eksternal } \\
\hline No. & Opportunities (Peluang) & No. & Threats (Ancaman) \\
\hline 1 & $\begin{array}{l}\text { Dapat menjalin kerjasama } \\
\text { dengan vendor transportasi } \\
\text { umum }\end{array}$ & 1 & $\begin{array}{l}\text { Menurut informasi yang } \\
\text { didapat lahan Kampus } \\
\text { Itenas akan berkurang } 7 \mathrm{~m} \\
\text { di area depan akibat adanya } \\
\text { pembangunan jalan layang } \\
\text { sepanjang Jalan PHH. } \\
\text { Mustofa }\end{array}$ \\
\hline \multirow[t]{2}{*}{2} & $\begin{array}{l}\text { Peraturan Wali Kota } \\
\text { (perwal) baru Nomor } \\
1023 / 2016 \text { Tentang } \\
\text { Bangunan Gedung Hijau, } \\
\text { yang mengharuskan setiap } \\
\text { bangunan yang akan } \\
\text { dibangun harus memiliki } \\
\text { konsep green building }\end{array}$ & 2 & $\begin{array}{l}\text { Kualitas dan kuantitas } \\
\text { terkait konsep green } \\
\text { building untuk kampus lain } \\
\text { lebih maju dibandingkan } \\
\text { Itenas }\end{array}$ \\
\hline & & & $\begin{array}{l}\text { Meningkatnya jumlah } \\
\text { kendaraan pribadi }\end{array}$ \\
\hline \multicolumn{4}{|c|}{$\begin{array}{l}\text { Dari hasil analisis SWOT selanjutnya dibuat strategi } \\
\text { dari kekuatan, kelemahan, peluang, dan ancaman } \\
\text { seperti pada Tabel } 4 \text {. }\end{array}$} \\
\hline
\end{tabular}

Tabel 4. Strategi SWOT

\begin{tabular}{cl}
\hline No. & \multicolumn{1}{c}{ Strategi Strengths dan Opportunities } \\
\hline 1 & $\begin{array}{l}\text { Lahan tidur di Itenas yang cukup luas masih dapat } \\
\text { dimanfaatkan }\end{array}$ \\
\hline 2 & $\begin{array}{l}\text { Adanya usaha untuk penghematan sumber energi yaitu akan } \\
\text { digunakannya solar panel }\end{array}$ \\
\hline 3 & $\begin{array}{l}\text { Usaha pengurangan kendaraan pribadi dengan bekerjasama } \\
\text { dengan vendor }\end{array}$ \\
\hline 4 & $\begin{array}{l}\text { Penghematan finansial dari adanya biaya parkir serta } \\
\text { penggunaan energi diperkecil }\end{array}$ \\
\hline No. & \multicolumn{1}{c}{ Strategi Weaknesses dan Opportunities } \\
\hline 1 & $\begin{array}{l}\text { Mengadakan seminar tentang pentingnya pembangunan } \\
\text { berkelanjutan }\end{array}$ \\
\hline 2 & $\begin{array}{l}\text { Menanam tanaman baru untuk menambah lahan hijau di lahan } \\
\text { tidur }\end{array}$ \\
\hline 3 & $\begin{array}{l}\text { Membuat vertical garden untuk memenuhi Perwal Kota } \\
\text { Bandung tentang bangunan hijau }\end{array}$ \\
\hline 4 & Pengurangan lahan parkir untuk menambah RTH \\
\hline No. & \multicolumn{1}{c}{ Strategi Strengths dan Threats } \\
\hline 1 & $\begin{array}{l}\text { Menanam tanaman untuk kebutuhan yang akan datang, karena } \\
\text { diketahui bahwa lahan Itenas akan berkurang akibat } \\
\text { pembangunan jalan layang sepanjang JalanPHH. Mustofa }\end{array}$ \\
\hline 2 & $\begin{array}{l}\text { Kampanye tentang penggunaan sepeda karena lokasi Itenas } \\
\text { cukup strategis }\end{array}$ \\
\hline 3 & $\begin{array}{l}\text { Mengadakan seminar nasional tentang green building atau } \\
\text { green campus }\end{array}$ \\
\hline No. & $\begin{array}{l}\text { Meningkatkan kerjasama antar jurusan di Kampus Itenas untuk } \\
\text { pembangunan berkelanjutan }\end{array}$ \\
\hline 2 & $\begin{array}{l}\text { Meningkatkan dukungan dari Pemerintah Kota Bandung } \\
\text { dalam menerapkan konsep green building di Itenas }\end{array}$ \\
\hline 3 & $\begin{array}{l}\text { keningkatkan minat sivitas akademika untuk menggunakan } \\
\text { kendaraan umum }\end{array}$ \\
\hline 1 &
\end{tabular}

\section{KESIMPULAN}

Dari hasil penilaian yang didapat untuk Gedung 1 yaitu pada kriteria pemilihan tapak, aksesibilitas komunitas, transportasi umum, dan iklim mikro;sehingga untuk memperbaiki nilai yang belum didapat perlu ada penanganan khusus terhadap kriteria fasilitas pengguna sepeda seperti menambah lahan parkir hijau minimal untuk 20 unit sepeda, lansekap pada lahanuntuk menambah vegetasi hijau seperti membangun RTNH di lahan tidur, pada iklim mikro membuat roof garden atau vertical garden, dan manajemen air limpasan hujan seperti membuat sumur resapan air untuk mengurangi volume drainase agar dapat memenuhi target yang diharapkan. Sedangkanhasil penilaian yang didapat untuk Gedung Student Center yaitu pada kriteria community accessibility, site landscaping, heat island effect, dan building neighbourhood; sehingga untuk memperbaiki nilai yang belum didapatperlu ada penanganan khusus terhadap kriteria pengurangan jumlah pengguna kendaraan pribadi, memberikan fasilitas yang nyaman untuk pejalan kaki, dan menggunakan jenis tanaman tertentu untuk dapat menarik satwa non peliharaanagar diharapkan dapat memenuhi nilai target yang sudah ditentukan.

\section{DAFTAR PUSTAKA}

[1] Institut Teknologi Nasional, "Visi dan Misi", dalam ITENAS Visi dan Misi, dipetik 22 November 2017 dari: http://www.itenas.ac.id/in/page/visi-dan-misi1205240641

[2] World Commission on Environment and Development (WCED), "Our Common Future", Oxford, Oxford University Press, 1987.

[3] Green Building Council Indonesia, "Tentang GBC Indonesia",dipetik 22 November 2017 dari Green Building Council Indonesia Home: http://www.gbcindonesia.org/

[4] Green Building Council Indonesia, (2014, Februari 04),“GREENSHIP New Building”, dipetik 22 November 2017 dariGreen Building Council Indonesia:http://www.gbcindonesia.org/greenship/rati ng-tools/download/cat_view/4greenship/5-greenshipnew-building

[5] Green Building Council Indonesia, (2012, September 08),“GREENSHIP Existing Building”, dipetik 22 November 2017 dariGreen Building Council Indonesia:http://www.gbcindonesia.org/greenship/rati ng-tools/download/cat_view/4-greenship/6greenship-existing-building. 